\title{
Analysis of the Effect of Progressive Speed Training on Tribal and Non-tribal School Boys
}

\author{
Shaybal Chanda ${ }^{*}$, Chandra Sankar Hazari, Sumanta Kumar Mondal \\ Department of Physical Education and Sport Science, Institute of Education, Visva-Bharati University, Santiniketan, India \\ Email address: \\ shaybalchanda@yahoo.com (S. Chanda), chandhazari6@gmail.com (C. S. Hazari), sumantakr.mondal@visva-bharati.ac.in (S. K. Mondal) \\ ${ }^{*}$ Corresponding author
}

To cite this article:

Shaybal Chanda, Chandra Sankar Hazari, Sumanta Kumar Mondal. Analysis of the Effect of Progressive Speed Training on Tribal and Nontribal School Boys. American Journal of Sports Science. Vol. 9, No. 3, 2021, pp. 66-72. doi: 10.11648/j.ajss.20210903.12

Received: August 8, 2021; Accepted: August 20, 2021; Published: September 13, 2021

\begin{abstract}
Sprint training should start at the early stages of the athletes considering the importance of it as one of the most important motor abilities to achieve the best performance of the athlete at the desired age. The study aims to identify the progression of progressive speed training basis on the duration of training of the Santali tribe and Bengali high school boys. Subjects were Santali tribe and Bengali adolescent schoolboys and their ages ranged between 13 to 15 years selected from Bankura District of West Bengal, India. These two groups were further divided into control and experimental groups and in each of the groups, there were 20 students. Initially, 4 weeks of uniform conditioning training was given to all groups before the pretest T1 was conducted. Further, consecutively 3 more post-tests (T2, T3, \& T4) were conducted after every 4 weeks providing progressive speed training. In the descriptive part Mean trimming was revealed. For the comparison of performed Tests timing, MANOVA, ANOVA, and LSD post hock test were employed. The result of the study reveals that Non-tribal (Bengali) and Tribal (Santali) adolescent schoolboys responded positively with the designed progressive speed training. This progression of sprint test timing took place progressively over time on the Bengali and Santali boys distinctly within the groups. Progression of Bengali boys took place from Test 1 to Test 2 numerically but not statistically, which is the dissimilarity in the process of progression of speed ability with the Santali boys. It is concluded that alike progressive speed training is equally effective for the Santali tribe and Bengali schoolboys but the progression of Bengali Boys begins a bit slower in the early stages than the Santali tribe in the sprint ability.
\end{abstract}

Keywords: Progressive Sprint Training, Santali, Bengali, Adolescent

\section{Introduction}

To bring the athletes to the topmost position in a competition Coaches need to take cutting edge preparation in training in this $21^{\text {st }}$ century of the advanced technological era. The prime need of all sports is to develop all the motor abilities of the athletes including speed for maximum output of their sports performance. To keep own athletes edge over the competition, developing their sprinting ability has enormous importance [1]. The higher velocity of a sprint only can be attained by multiplying stride frequency with stride length [2]. For the improvement of sprinting speed, both aspects must be improved [3]. In addition, reaching the utmost velocity as fast as possible is another essential ability of the player that also needs to address properly [4]. Stride length in sprinting is a mechanical issue of Biomechanics that depends greatly on skeletal and postural structure and economic use of these [5]. The myocellular foundation of the muscles is a determinant factor for success in high-level sprint competition [6].

Many pieces of research took place on sprint training because it is one of the vital capabilities that determine the better performance of most sports [7]. There are a large number of established training methods available to the knowledge base of the science of sports training to augment the sprinting ability of the players [8-10]. Developing sprinting ability is a lifelong process and growth, maturity, training, and the aging process are the determinant factor [7, $11,12]$. By ensuring proper recovery in the long term progressive loading training, it is only possible to achieve and sustain performance [13], this type of training reduces the risk of injury and further development of performance. 
There is a great danger of injury if the loading process takes place faster than adaptation and increased illicitly [14].

Each population groups vary according to their body structure, mass, growth, and figure [15]. These differences exist in different ethnic groups due to the genetic and environmental mysterious amalgamation [16]. The major three distinguishable races are Mongoloid or Asiatic, Caucasian or White, and Negroid or Black [17]. These groups stand alone based on their different traits. Differences within a racial group do not limit themselves [18-21] but also distinct features of anthropology and morphology are evidenced in its subdivisions [22]. Designing a uniform standard for all racial groups and their subdivisions is an unrealistic approach [23].

Santali population anthropologically belongs to the ProtoAustraloid group [24]. The Santali population is short in height, skin color is dark brown to nearly black, the head is dolichocephalic, the nose is broad \& flat and depressed at the root, hair is wavy and/or curly, and supraorbital ridges are prominent [25]. Bengali people originated from an IndoAryan ethnic group [26]. Some other findings also suggest that genetic traces exist in the Bengali population of ProtoAutraloids, Mongoloids, and Caucasoids, these influences shaped Bengali as broad head, dark in complexion, plentiful hair on the face, built with medium stature, medium nose [27]. Therefore, it is clear that there is a difference in anthropology and morphology between Santali and Bengali populations though they share the same land as habitant. Thus, the purpose of the study is to identify whether there is any difference in response to the progressive speed training between Bengali and Santali adolescent boys. The study aims at identifying the progression of progressive speed training basis on the duration of training of the Santali tribe and Bengali young boys.

\section{Method and Materials}

\subsection{Selection of Subject}

Subjects racially belong to the Bengali and Santali tribe. These two groups were further divided randomly into control and experimental groups. In each group, there were 20 students and altogether 80 students for 4 groups in the study. The age range of the students was 13 to 15 years. The speed training was administered in the year 2018 for subsequent data collection.

Training Protocol

Firstly, the stratified sampling method was adopted for strata school students into Bengali and Santali Tribe. Secondly, the random sampling method was adopted on both the primary groups to subdivide into control and experimental groups. All the selected students have been given identical 4 weeks of conditioning training of general nature, then their performance in 60 miter sprint test was recorded. Further, 4 weeks of progressive speed training have been given on experimental groups only in 3 spells and then after every spell of training same test was repeated on the experimental and control groups to collect time data.

Table 1. Pre Test Conditioning Training for All for 4 Weeks.

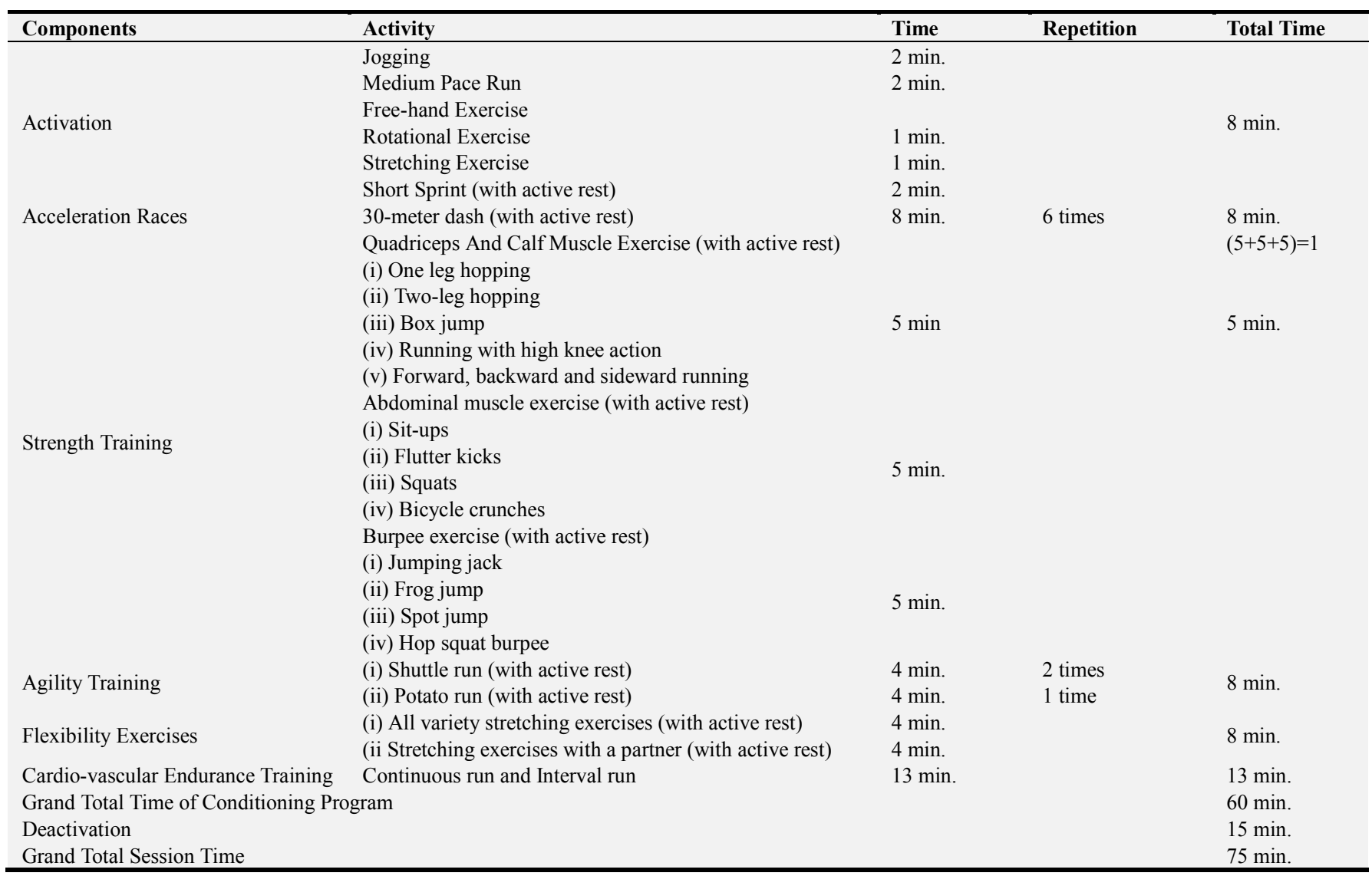


Table 2. Progressive Speed Training Schedule.

\begin{tabular}{|c|c|c|c|c|c|c|}
\hline \multirow[b]{2}{*}{ Week } & \multirow{2}{*}{$\begin{array}{l}\text { Preparatory } \\
\text { phase (General } \\
\text { warming-up) }\end{array}$} & \multicolumn{5}{|l|}{ Specific Warming up } \\
\hline & & Speed Training Item (General) & $\begin{array}{l}\text { Frequency } \\
\text { Repetition }\end{array}$ & Duration & Active Rest & $\begin{array}{l}\text { Total } \\
\text { Duration }\end{array}$ \\
\hline $1^{\text {st }}-4^{\text {th }}$ & $10 \mathrm{~min}$. & $\begin{array}{l}10 \text { Items: Jump Squat, Jump Lunges, } \\
\text { Lateral Bound, A Skips, Reverse Lunge } \\
\text { Knee Drive, Tuck Jump, High Knees, Heel } \\
\text { Flicks, Kneeling Jumps, and Calf Jumps. }\end{array}$ & $\begin{array}{l}\text { One time } \\
\text { each }\end{array}$ & $\begin{array}{l}5 \mathrm{~min} . \text { (Each item } \\
30 \mathrm{sec} \text {.) }\end{array}$ & $4 \mathrm{~min} .30 \mathrm{sec}$. & $\begin{array}{l}19 \min .30 \\
\text { sec. }\end{array}$ \\
\hline $5^{\text {th }}-8^{\text {th }}$ & $10 \mathrm{~min}$. & Do & $\begin{array}{l}\text { Two times } \\
\text { each }\end{array}$ & $\begin{array}{l}10 \mathrm{~min} . \\
\text { (Each item } 30 \mathrm{sec} .+ \\
30 \mathrm{sec} .)\end{array}$ & $\begin{array}{l}4 \mathrm{~min} .30 \mathrm{sec} .+1 \mathrm{~min} .+4 \\
\min .30 \mathrm{sec} .=10 \mathrm{~min} .\end{array}$ & $30 \mathrm{~min}$. \\
\hline $9^{\text {th }}-12^{\text {th }}$ & $10 \mathrm{~min}$. & Do & $\begin{array}{l}\text { three times } \\
\text { each }\end{array}$ & $\begin{array}{l}15 \mathrm{~min} . \\
\text { (Each item } 30 \mathrm{sec} .+ \\
30 \mathrm{sec} .+30 \mathrm{sec} .)\end{array}$ & $\begin{array}{l}4 \mathrm{~min} .30 \mathrm{sec} .+1 \mathrm{~min} .+4 \\
\min .30 \mathrm{sec} .+1 \mathrm{~min} .+4 \mathrm{~min} . \\
30 \mathrm{sec} .=15 \mathrm{~min} .30 \mathrm{sec} .\end{array}$ & $\begin{array}{l}40 \mathrm{~min} .30 \\
\text { sec. }\end{array}$ \\
\hline
\end{tabular}

Table 2. Continued.

\begin{tabular}{|c|c|c|c|}
\hline \multirow{2}{*}{ Week } & \multicolumn{3}{|l|}{ Specific speed training program } \\
\hline & Day-1 & Day-2 & Day-3 \\
\hline $1^{\text {st }}-4^{\text {th }}$ & $\begin{array}{l}\text { 80-meter run, } \\
90 \text {-meter run, } \\
110 \text {-meter run, } \\
120 \text {-meter run and } 150 \text {-meter run. } \\
\text { (Walk back recovery } 70 \%-80 \% \text { intensity). }\end{array}$ & $\begin{array}{l}\text { ( } 30 \text { meter run } \times 3 \text { time }) \times 2 \text { repetition. } \\
(50 \text { meter run } \times 2 \text { time }) \times 2 \text { repetition. } \\
\text { ( } 80 \text { meter run } \times 2 \text { time }) \times 1 \text { repetition. } \\
\text { (Walk back recovery } 60 \%-80 \% \text { intensity). }\end{array}$ & $\begin{array}{l}\text { ( } 80 \text { meter run } \times 3 \text { time) } \times 1 \text { repetition. } \\
\text { ( } 90 \text { meter run } \times 2 \text { time }) \times 1 \text { repetition. } \\
\text { ( } 110 \text { meter run } \times 2 \text { time }) \times 1 \text { repetition. } \\
\text { (120 meter run } \times 1 \text { time }) \times 1 \text { repetition. } \\
\text { (Walk back recovery } 60 \%-80 \% \text { intensity). }\end{array}$ \\
\hline $5^{\text {th }}-8^{\text {th }}$ & $\begin{array}{l}\text { ( } 30 \text { meter run } \times 3 \text { time }) \times 3 \text { repetition. } \\
\text { ( } 40 \text { meter run } \times 2 \text { time }) \times 3 \text { repetition. } \\
(50 \text { meter run } \times 1 \text { time }) \times 3 \text { repetition. }\end{array}$ & $\begin{array}{l}\text { 110-meter run, } \\
\text { 90-meter run, } \\
\text { 80-meter run, } \\
\text { 90-meter run and 110-meter run. } \\
\text { (Sub maximum effort). }\end{array}$ & $\begin{array}{l}\text { ( } 60 \text { meter run } \times 2 \text { time }) \times 2 \text { repetition. } \\
\text { ( } 80 \text { meter run } \times 1 \text { time }) \times 2 \text { repetition } \\
\text { ( } 90 \text { meter run } \times 2 \text { time }) \times 1 \text { repetition. } \\
\text { (Sub maximum effort). }\end{array}$ \\
\hline $9^{\text {th }}-12^{\text {th }}$ & $\begin{array}{l}\text { ( } 30 \text { meter run } \times 3 \text { time }) \times 4 \text { repetition. } \\
\text { ( } 40 \text { meter run } \times 3 \text { time }) \times 4 \text { repetition. } \\
\text { ( } 50 \text { meter run } \times 2 \text { time }) \times 2 \text { repetition. } \\
\text { (Full effort). }\end{array}$ & $\begin{array}{l}\text { 80-meter run, } \\
90 \text {-meter run, } \\
\text { 110-meter run and } 120 \text {-meter run. } \\
\text { (Maximum effort). }\end{array}$ & $\begin{array}{l}\text { ( } 60 \text { meter run } \times 2 \text { time }) \times 2 \text { repetition. } \\
\text { ( } 80 \text { meter run } \times 3 \text { time }) \times 1 \text { repetition. } \\
\text { ( } 90 \text { meter run } \times 2 \text { time) }) 1 \text { repetition. } \\
\text { (Maximum effort). }\end{array}$ \\
\hline
\end{tabular}

\subsection{Materials}

For the collection of the timing as data of 60 meter (m) speed test standard stopwatch was used, to record the given performance score sheets, and a well-marked track on the grass field were used too for data collection.

\subsection{Scoring Method}

Timekeepers had been given sufficient enough practice to familiarize themselves with the stopwatch operation well before data collection. Participants took the required individual warm-up time before the 60-meter speed test. They had been given enough verbal and practical demonstration of the test and motivation before taking the test. The timing of a single trial was recorded as a test score.

\subsection{Statistical Procedure}

In the descriptive statistics, Mean valued has been revealed to see numerical differences. To establish the differences in the performances one-way MANOVA \&ANOVA, and LSD as a post hoc test has been employed. The level of significance was $\alpha=0.05$.

\section{Analysis of Data and Results}

\subsection{Analysis of Data}

Bar Chart Figure 1 of 60 -meter Sprint test mean timing for numeric interpretation of four tests within each group shows that in the Experimental groups' tests timings sharply decline that means performance improved as non-tribal (Bengali) Experimental mean timing T1, T2, T3, \& T4 are 9.95, 9.47, $9.00 \& 8.61$ respectively, and tribal (Santali) Experimental mean timing T1, T2, T3, \& T4 are 10.03, 9.52, $8.99 \& 8.26$ respectively. On the other hand, in both the Control groups slightly performance decline that the mean timings of the tests more or less increased with slight fluctuation as non-tribal Control mean timing 10.09, 10.20, $10.27 \& 10.24$ successively of $\mathrm{T} 1, \mathrm{~T} 2, \mathrm{~T} 3, \& \mathrm{~T} 4$, and tribal Control mean timing $10.06,10.19,10.18$ \& 10.24 successively of T1, T2, T3, \& T4. 


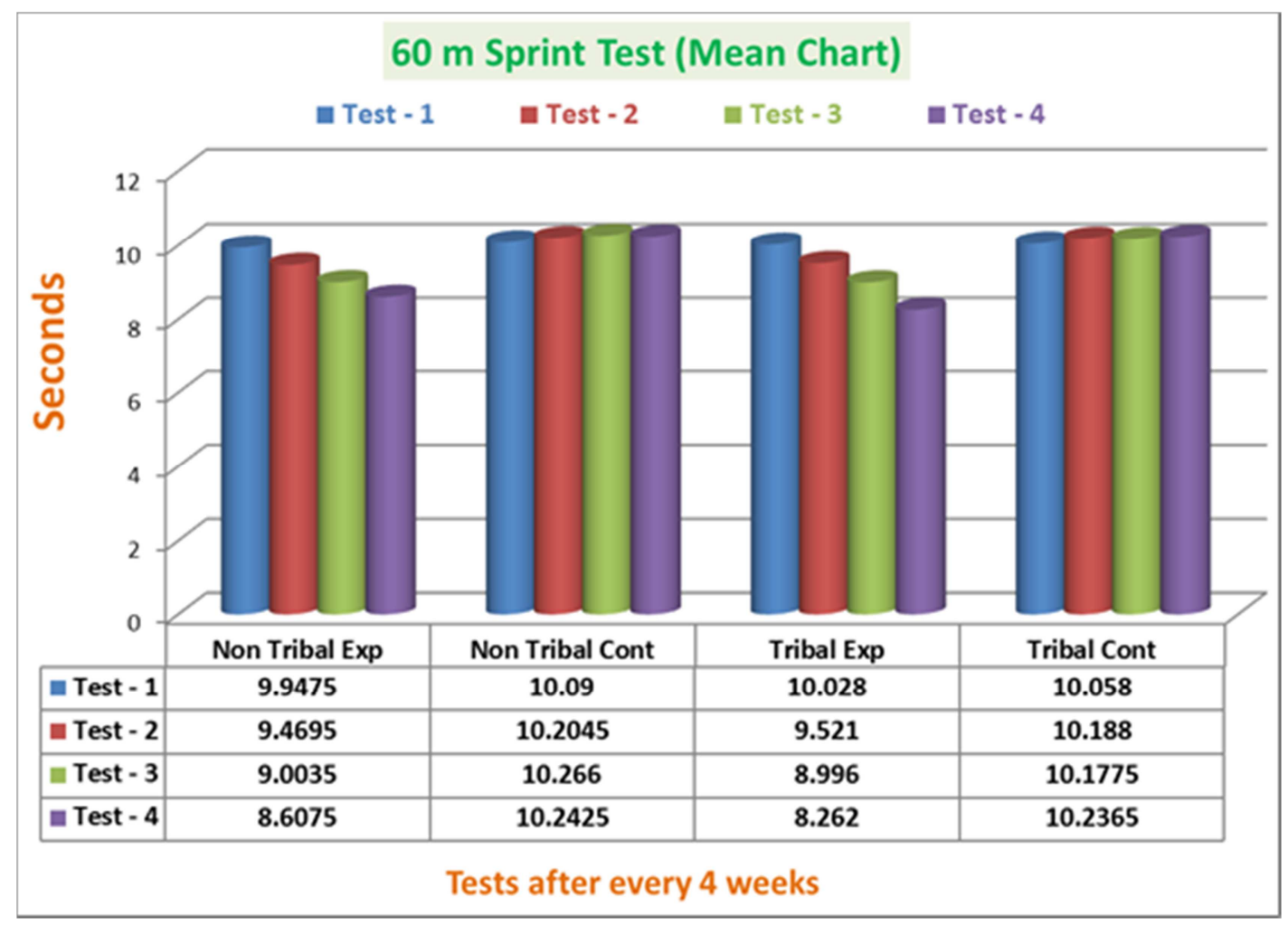

Figure 1. $60 \mathrm{~m}$ Sprint Test Mean Chart within the Groups.

Table 3. MANOVA Test Table of $60 \mathrm{~m}$ Sprint Test among the Groups.

\begin{tabular}{|c|c|c|c|c|c|c|c|c|}
\hline Effect & & Value & $\mathbf{F}$ & Hypothesis df & Error df & Sig. & Partial Eta Squared & Observed Power $^{\mathrm{d}}$ \\
\hline \multirow{5}{*}{ Intercept } & Pillai's Trace & .999 & $20467.394^{\mathrm{b}}$ & 4.000 & 73.000 & .000 & .999 & 1.000 \\
\hline & Wilks' Lambda & .001 & $20467.394^{\mathrm{b}}$ & 4.000 & 73.000 & .000 & .999 & 1.000 \\
\hline & Hotelling's Trace & 1121.501 & $20467.394^{\mathrm{b}}$ & 4.000 & 73.000 & .000 & .999 & 1.000 \\
\hline & Roy's Largest Root & 1121.501 & $20467.394^{b}$ & 4.000 & 73.000 & .000 & .999 & 1.000 \\
\hline & Pillai's Trace & .612 & 4.804 & 12.000 & 225.000 & .000 & .204 & 1.000 \\
\hline Between & Wilks' Lambda & .395 & 6.777 & 12.000 & 193.431 & .000 & .266 & 1.000 \\
\hline \multirow[t]{2}{*}{ Tests } & Hotelling's Trace & 1.513 & 9.037 & 12.000 & 215.000 & .000 & .335 & 1.000 \\
\hline & Roy's Largest Root & 1.501 & $28.150^{\mathrm{c}}$ & 4.000 & 75.000 & .000 & .600 & 1.000 \\
\hline \multicolumn{9}{|c|}{$\begin{array}{l}\text { a. Design: Intercept }+ \text { Between Tests } \\
\text { b. Exact statistic } \\
\text { c. The statistic is an upper bound on F that yields a lower bound on the significance level. } \\
\text { d. Computed using alpha }=.05\end{array}$} \\
\hline
\end{tabular}

The result of MANOVA Table 3 describes that there was a statistically significant difference in the four groups together, non-tribal Control \& Experimental, and tribal Control \& Experimental pretest in $60 \mathrm{~m}$ Sprint test performance after every four weeks of speed training, on the combined dependent variable, Pillai's Trace $=.612, F(12,225)=4.804$, $p<.001$, partial $\eta^{2}=.204$, observed power $=1.00$. Based on the result, evidence was enough to reject the null hypothesis and conclude that tests combined significantly differed based on the type of tests conducted. The effect size of the test was large. Cohen (1962, p 368) suggests that effect size: small $=.01$, medium $=.06$, and large $=.14[28,29]$. The observed power was 1.00 , demonstrating that there was a $100 \%$ possibility that the outcome could have come out significant.

Table 4. ANOVA Tests of Between-Subjects Effects.

\begin{tabular}{|c|c|c|c|c|c|c|c|}
\hline Source & Dependent Variable & df & Mean Square & $\mathbf{F}$ & Sig. & Partial Eta Squared & Observed Power $^{\mathrm{e}}$ \\
\hline \multirow{4}{*}{ Between Tests } & Non-tribal Exp. & 3 & 6.720 & 4.686 & .005 & .156 & .880 \\
\hline & Non-tribal Cont. & 3 & .122 & .241 & .867 & .009 & .094 \\
\hline & Tribal Exp. & 3 & 11.400 & 30.770 & .000 & .548 & 1.000 \\
\hline & Tribal Cont. & 3 & .115 & .403 & .751 & .016 & .127 \\
\hline \multirow{3}{*}{ Error } & Non-tribal Exp. & 76 & 1.434 & & & & \\
\hline & Non-tribal Cont. & 76 & .505 & & & & \\
\hline & Tribal Exp. & 76 & .371 & & & & \\
\hline e. Computed us & & & & & & & \\
\hline
\end{tabular}


Table 4 describes that each ANOVA was tested with the Bonferroni method at $\alpha=.05$ level. Results confirmed that there was enough evidence to reject the null hypothesis for Non-tribal Experimental and tribal Experimental groups' post-tests. Non-tribal Experimental Group: $F(3,76)=$ 4.686, $p>.001$, partial $\eta^{2}=.156$, observed power $=.880$. Tribal Experimental Group: $F(3,76)=30.770, p<.001$, partial $\eta^{2}=.548$, observed power $=1.000$. The effect size of both the Experimental groups was large for all post-test
ANOVAs. Statistically, significant differences exist among the dependent variables' scores of both tribal and Non-tribal Experimental Groups. The observed power of $.880 \& 1.000$ respectively for the Non-tribal Experimental group and tribal Experimental group indicated that there were $88 \%$, \& $100 \%$ chances that the result could have come out significant for all analyses. On the contrary, no statistically significant differences have been reported in both control groups.

Table 5. Multiple Comparisons among Dependent Variables within the Test, LSD.

\begin{tabular}{|c|c|c|c|c|c|}
\hline Dependent Variable & (I) Between Tests & (J) Between Tests & Mean Difference (I-J) & Std. Error & Sig. \\
\hline \multirow{13}{*}{ Non-tribal Exp. } & \multirow{3}{*}{ Test 1} & Test 2 & .4780 & .37872 & .211 \\
\hline & & Test 3 & $.9440^{*}$ & .37872 & .015 \\
\hline & & Test 4 & $1.3400^{*}$ & .37872 & .001 \\
\hline & \multirow{3}{*}{ Test 2} & Test 1 & -.4780 & .37872 & .211 \\
\hline & & Test 3 & .4660 & .37872 & .222 \\
\hline & & Test 4 & $.8620^{*}$ & .37872 & .026 \\
\hline & \multirow{3}{*}{ Test 3} & Test 1 & $-.9440^{*}$ & .37872 & .015 \\
\hline & & Test 2 & -.4660 & .37872 & .222 \\
\hline & & Test 4 & .3960 & .37872 & .299 \\
\hline & \multirow{4}{*}{ Test 4} & Test 1 & $-1.3400^{*}$ & .37872 & .001 \\
\hline & & Test 2 & $-.8620^{*}$ & .37872 & .026 \\
\hline & & Test 3 & -.3960 & .37872 & .299 \\
\hline & & Test 2 & -.1145 & .22472 & .612 \\
\hline \multirow{11}{*}{ Non-tribal Cont. } & \multirow[t]{2}{*}{ Test 1} & Test 3 & -.1760 & .22472 & .436 \\
\hline & & Test 4 & -.1525 & .22472 & .499 \\
\hline & \multirow{3}{*}{ Test 2} & Test 1 & .1145 & .22472 & .612 \\
\hline & & Test 3 & -.0615 & .22472 & .785 \\
\hline & & Test 4 & -.0380 & .22472 & .866 \\
\hline & \multirow{3}{*}{ Test 3} & Test 1 & .1760 & .22472 & .436 \\
\hline & & Test 2 & .0615 & .22472 & .785 \\
\hline & & Test 4 & .0235 & .22472 & .917 \\
\hline & \multirow{4}{*}{ Test 4} & Test 1 & .1525 & .22472 & .499 \\
\hline & & Test 2 & .0380 & .22472 & .866 \\
\hline & & Test 3 & -.0235 & .22472 & .917 \\
\hline \multirow{12}{*}{ Tribal Exp. } & & Test 2 & $.5070^{*}$ & .19248 & .010 \\
\hline & \multirow[t]{2}{*}{ Test 1} & Test 3 & $1.0320^{*}$ & .19248 & .000 \\
\hline & & Test 4 & $1.7660^{*}$ & .19248 & .000 \\
\hline & \multirow{3}{*}{ Test 2} & Test 1 & $-.5070^{*}$ & .19248 & .010 \\
\hline & & Test 3 & $.5250^{*}$ & .19248 & .008 \\
\hline & & Test 4 & $1.2590^{*}$ & .19248 & .000 \\
\hline & \multirow{3}{*}{ Test 3} & Test 1 & $-1.0320^{*}$ & .19248 & .000 \\
\hline & & Test 2 & $-.5250^{*}$ & .19248 & .008 \\
\hline & & Test 4 & $.7340^{*}$ & .19248 & .000 \\
\hline & \multirow{3}{*}{ Test 4} & Test 1 & $-1.7660^{*}$ & .19248 & .000 \\
\hline & & Test 2 & $-1.2590^{*}$ & .19248 & .000 \\
\hline & & Test 3 & $-.7340^{*}$ & .19248 & .000 \\
\hline \multirow{12}{*}{ Tribal Cont. } & \multirow{3}{*}{ Test 1} & Test 2 & -.1300 & .16885 & .444 \\
\hline & & Test 3 & -.1195 & .16885 & .481 \\
\hline & & Test 4 & -.1785 & .16885 & .294 \\
\hline & \multirow{3}{*}{ Test 2} & Test 1 & .1300 & .16885 & .444 \\
\hline & & Test 3 & .0105 & .16885 & .951 \\
\hline & & Test 4 & -.0485 & .16885 & .775 \\
\hline & \multirow{3}{*}{ Test 3} & Test 1 & .1195 & .16885 & .481 \\
\hline & & Test 2 & -.0105 & .16885 & .951 \\
\hline & & Test 4 & -.0590 & .16885 & .728 \\
\hline & \multirow{3}{*}{ Test 4} & Test 1 & .1785 & .16885 & .294 \\
\hline & & Test 2 & .0485 & .16885 & .775 \\
\hline & & Test 3 & .0590 & .16885 & .728 \\
\hline
\end{tabular}

Table 5 Explains that each comparison was made with 
comparisons illustrates an interesting result that in the post test $60 \mathrm{~m}$ Sprint Non-tribal Experimental group significant statistical differences have been made in the comparison between Test-1 $(M=9.95)$ with Test- $3(M=9.00)$ \& Test- 4 $(M=8.61)$, Test- $2(M=9.47) \&$ Test- $4(M=8.61)$, Further, in the $60 \mathrm{~m}$ Sprint Tribal Experimental group statistically significant differences have been observed in the comparison of Test-1 $(M=10.03)$ with Test- $2(M=9.52)$ \& Test- $3(M$ $=8.99) \&$ Test- $4(M=8.26)$, Test- $2(M=9.52) \&$ Test- $3(M$ $=8.99) \&$ Test- $4(M=8.26)$, Test- $3(M=8.99) \&$ Test- $4(M$ $=8.26)$. In contrast, no statistical significant difference is observed in the tests' scores within the control groups.

\subsection{Results}

$60 \mathrm{~m}$ sprint test timing persistently decreased that mean performance improved for both the experimental groups of the Bengali and the Santali tribe. On the other hand, control groups of the Santali tribe and Bengali students almost slightly progressively increased test timing that means performance decreased progressively in the $60 \mathrm{~m}$ sprint test. Further, resolute of the progressive speed training reflected on experimental groups as all the test scores differ significantly with each other within the experimental groups of Santali tribe and Bengali adolescence schoolboys with an exception between Test-1 \&Test-2 of the Bengali students although numeric progress is evidenced.

\section{Discussions}

$60 \mathrm{~m}$ sprint test timing persistently decreased that mean performance improved for both the experimental groups of the Bengali and the Santali tribe. The phenomenon of progression of continuous performance of sprint test timing most probably has resulted in both the experimental groups of the Santali and Bengali students due to the positive effect of progressive speed training. As well planned long-term progressive loading training ensures performance development and sustainability [13]. The distinct nature of speed performance development takes place due to the racial differences that exist between these two groups [16], though they inhabit the same geographic area. The racial groups and even sub-divisions of these racial groups respond differently with speed training [23]. Since distinct features of anthropology and morphology are evidenced among the major racial divisions and in subdivisions of these [22]. Bengali people originated from an Indo-Aryan ethnic group [26] and genetic traces exist in the Bengali population of Proto-Autraloids, Mongoloids, and Caucasoids [27]. In contrast, the Santali tribe anthropologically belongs to the Proto-Australoid group [24]. This racial difference might have played a role differently in the pattern of speed development. On the other hand, control groups of the Santali tribe and Bengali students almost slightly increased test timing progressively that the mean performance of the $60 \mathrm{~m}$ sprint test timing progressively decreased. Among the students of control groups of tribal and non-tribal students almost continuous deterioration in test performance phenomenon occurred may be due to not to receive any training persistently after conditioning training as their counterparts. Reasons may be the same as described for the result of significant difference in the improvement of the speed test performance within the experimental groups and not becoming statistically significant difference within the control groups of both the groups of Santali tribe and Bengali adolescent boys. The reason to display different patterns in the development of sprint performance in the experiment groups may be due to a few racial differences that exist between the Bengali and Santali tribe [24, 26, 27]. As scientific progressively loaded speed training only ensure improvement of performance [7, $11,12,30]$, leading to the assumption that control groups successively lose their performances in the mean values over the time as they were withdrawn from the training after the conditioning program despite no significant statistical difference was evidenced.

\section{Conclusion}

Alike progressive speed training is equally effective for the Santali tribe and Bengali schoolboys but the progression of Bengali Boys begins a bit slower in the early stages than the Santali tribe in the sprint ability.

\section{Recommendation}

The findings of the present study would help Physical Education Teachers and Coaches to provide progressive speed training to Bengali and Santali tribe schoolboys and understanding their unique performance development phenomenon. Further research on the same topic with larger sample size and the cohort of different age groups may reveal better perception as the populations of these two ethnicities are large enough.

\section{References}

[1] M. J. M. Behrens, S. R. E. Simonson, A Comparison of the Various Methods Used To Enhance Sprint Speed, Strength $\begin{array}{lllll}\text { Cond. } & \text { J. } & 33 & \text { (2011) } & \text { 64-71. }\end{array}$ https://doi.org/10.1519/SSC.0b013e318210174d.

[2] G. Paradisis, C. Cooke, The effects of sprint running training on sloping surfaces. J Strength Cond Res 20: 767-777, 2006, J Strength Cond Res. 20 (2006). https://doi.org/10.1519/R-16834.1.

[3] G. Dintiman, R. Ward, Sports Speed, 3rd ed., Human Kinetics, 2003.

[4] A. Zafeiridis, P. Saraslanidis, V. Manou, P. Ioakimidis, K. Dipla, S. Kellis, The effects of resisted sled-pulling sprint training on acceleration and maximum speed performance, J. Sports Med. Phys. Fitness. 45 (2005) 284-290.

[5] N. E. Bezodis, S. Willwacher, A. I. T. Salo, The Biomechanics of the Track and Field Sprint Start: A Narrative Review, Sports Med. 49 (2019) 1345-1364. https://doi.org/10.1007/s40279-019-01138-1. 
[6] S. Trappe, N. Luden, K. Minchev, U. Raue, B. Jemiolo, T. A. Trappe, Skeletal muscle signature of a champion sprint runner, J. Appl. Physiol. 118 (2015) 1460-1466. https://doi.org/10.1152/japplphysiol.00037.2015.

[7] T. Haugen, S. Seiler, Ø. Sandbakk, E. Tønnessen, The Training and Development of Elite Sprint Performance: an Integration of Scientific and Best Practice Literature, Sports Med. - Open. 5 (2019) 44. https://doi.org/10.1186/s40798019-0221-0.

[8] D. Bishop, O. Girard, A. Mendez-Villanueva, Repeated-sprint ability - part II: recommendations for training, Sports Med. Auckl. $\quad$ NZ. $41 \quad$ (2011) 741-756. https://doi.org/10.2165/11590560-000000000-00000.

[9] M. C. Rumpf, R. G. Lockie, J. B. Cronin, F. Jalilvand, Effect of Different Sprint Training Methods on Sprint Performance Over Various Distances: A Brief Review, J. Strength Cond. Res. $\quad 30 \quad$ (2016) 1767-1785. https://doi.org/10.1519/JSC.0000000000001245.

[10] G. Petrakos, J.-B. Morin, B. Egan, Resisted Sled Sprint Training to Improve Sprint Performance: A Systematic Review, Sports Med. Auckl. NZ. 46 (2016) 381-400. https://doi.org/10.1007/s40279-015-0422-8.

[11] R. M. Malina, C. Bouchard, G. Beunen, Human Growth: Selected Aspects of Current Research on Well-Nourished Children, Annu. Rev. Anthropol. 17 (1988) 187-219. https://doi.org/10.1146/annurev.an.17.100188.001155.

[12] E. Tønnessen, I. S. Svendsen, I. C. Olsen, A. Guttormsen, T. Haugen, Performance development in adolescent track and field athletes according to age, sex and sport discipline, PloS $\begin{array}{llll}\text { One. } & 10 & \text { (2015) }\end{array}$ https://doi.org/10.1371/journal.pone.0129014.

[13] T. L. Delorme, A. L. Watkins, Technics of progressive resistance exercise, Arch. Phys. Med. Rehabil. 29 (1948) 263 273.

[14] T. J. Gabbett, The training-injury prevention paradox: should athletes be training smarter and harder? Br. J. Sports Med. 50 (2016) 273-280. https://doi.org/10.1136/bjsports-2015095788 .

[15] H. M. Rizvi, M. Z. Hossain, K. Tanee, Ethnical evaluation of Bangladeshi young adults in terms of morphometricallyanalyzed craniofacial skeleton, APOS Trends Orthod. 3 (2013) 15-22. https://doi.org/10.4103/2321-1407.112545.

[16] N. C. Harvey, P. A. Mahon, S. M. Robinson, C. E. Nisbet, M. K. Javaid, S. R. Crozier, H. M. Inskip, K. M. Godfrey, N. K. Arden, E. M. Dennison, C. Cooper, Different Indices of Fetal Growth Predict Bone Size and Volumetric Density at 4 Years of Age, J. Bone Miner. Res. Off. J. Am. Soc. Bone Miner. Res. 25 (2010) 920-927. https://doi.org/10.1359/jbmr.091022.

[17] L. J. Lee, Man's Most Dangerous Myth; The Fallacy of Race. By M. F. Ashley Montagu. (New York: Columbia University Press. 1942. Pp. xiii, 216. \$2.25.), Am. Polit. Sci. Rev. 37 (1943) 168-170. https://doi.org/10.2307/1949023.
[18] W. Bacon, P. Girardin, J. C. Turlot, A comparison of cephalometric norms for the African Bantu and a caucasoid population, Eur. J. Orthod. 5 (1983) 233-240. https://doi.org/10.1093/ejo/5.3.233.

[19] R. A. Drummond, A determination of cephalometric norms for the Negro race, Am. J. Orthod. 54 (1968) 670-682. https://doi.org/10.1016/0002-9416(68)90018-3.

[20] M. K. Guo, Cephalometric standards of Steiner analysis established on Chinese children, Taiwan Yi Xue Hui Za Zhi. 70 (1971) 97-102.

[21] F. Miura, N. Inoue, K. Suzuki, CEPHALOMETRIC STANDARDS FOR JAPANESE ACCORDING TO THE STEINER ANALYSIS, Am. J. Orthod. 51 (1965) 288-295. https://doi.org/10.1016/0002-9416(65)90103-x.

[22] R. A. Holdaway, A soft-tissue cephalometric analysis and its use in orthodontic treatment planning. Part I, Am. J. Orthod. 84 (1983) 1-28. https://doi.org/10.1016/0002-9416(83)901446.

[23] C. J. Kowalski, C. E. Nasjleti, G. F. Walker, Differential diagnosis of adult male black and white populations, Angle Orthod. 44 (1974) 346-350. https://doi.org/10.1043/00033219(1974)044<0346:DDOAMB >2.0.CO;2.

[24] N. Saha, J. S. H. Tay, A. C. Roy, M. K. Das, K. Das, M. Roy, B. Dey, S. Banerjee, B.N. Mukherjee, Genetic Study of Five Populations of Bihar, India, (1992) 12. http://library.isical.ac.in:8080/jspui/bitstream/10263/6779/1/G enetic $\% 20$ Study $\% 20$ of $\% 20$ Five $^{2} \% 20$ Populations $\% 20$ of $\% 20 \mathrm{Bi}$ har $\% 2 \mathrm{C} \% 20$ India.pdf.

[25] K. C. Malhotra, T. Vasulu, Development of typological classification and its relationship to microdifferentiation in ethnic India, J. Biosci. (2019). https://doi.org/10.1007/s12038019-9880-8.

[26] A. Chattopadhyay, A NOTE ON THE CONTRIBUTIONS OF THE "DRAVIDAS" TO THE ETHNICITY OF THE PEOPLE AND CULTURE OF BENGAL, Proc. Indian Hist. Congr. 61 (2000) 57-64. https://www.jstor.org/stable/44148079 (accessed July 28, 2021).

[27] B. N. Mukherjee, H. Walter, K. C. Malhotra, R. Chakraborty, P. Sauber, S. Banerjee, M. Roy, Population genetic study in ten endogamous groups of West Bengal, India, Anthropol. Anz. $\quad 45$ (1987) 239-254. https://www.jstor.org/stable/29539805 (accessed July 29, 2021).

[28] T. Schäfer, M. A. Schwarz, The Meaningfulness of Effect Sizes in Psychological Research: Differences Between SubDisciplines and the Impact of Potential Biases, Front. Psychol. 0 (2019). https://doi.org/10.3389/fpsyg.2019.00813.

[29] G. M. Sullivan, R. Feinn, Using Effect Size-or Why the P Value Is Not Enough, J. Grad. Med. Educ. 4 (2012) 279-282. https://doi.org/10.4300/JGME-D-12-00156.1.

[30] R. M. Malina, C. Bouchard, O. Bar-Or, Growth, Maturation, and Physical Activity, Human Kinetics, 2004. 